\title{
Updated Protocol for Management of Placenta Previa
}

\author{
Mazumder $\mathbf{U}^{1}$, KutubiA $^{2}$, Rouf $^{3}$
}

Conflict of Interest: There is no conflict of interest declared by all authors.

Received: 17 April 2017

Accepted: 22 May 2017 www.banglajol.info/index.php/JSSMC

\section{Key Words:}

Placenta previa; hemorrhage;

adverse consequences; ultrasound

\begin{abstract}
Background: Antepartum hemorrhage complicates 2-5\% of pregnancies, whichapproximately one-third are due to placenta previa. Placenta previa is acondition derived to an abnormal implantation of the embryos in thelower uterine segment. In placenta previa hemorrhage is more likely to occur during third trimester, as a consequence of the development of the lower uterine segment and of the dilation of the cervix due to the uterine contractions; alsovaginal examination may lead to an antepartum hemorrhage. Risk factors for the development of placenta previa include prior cesarean delivery, pregnancy termination, intrauterine surgery, smoking, multifetal gestation, increasing parity, maternal age and the rising rates of Cesarean section. Placenta previa is associated with adverse consequences for both mother and children, such as Intra-Uterine Growth Restriction (IUGR), preterm birth, antenatal and intra-partum hemorrhage, maternal blood transfusion and emergency hysterectomy. Placenta previa has been diagnosed increasingly in recent decades, due to mostly to the widespread use of ultrasound (US). Apart from ultrasound a valid imaging modality to study and investigate placenta in antepartum period seems to be magnetic resonance (MR).Careful monitoring of high risk pregnancies is of utmost importance. Avoidance of unnecessary caesarean sections and early week's pregnancy terminations can minimize the placenta previa. In diagnosed cases, preoperative planning, preoperative decisions and good postoperative management can safe a mother and child.
\end{abstract}

[J Shaheed Suhrawardy Med Coll 2017; 9(1): 26-30] DOI: http://dx.doi.org/10.3329/jssmc.v9i1.37256

\section{Introduction}

Antepartum hemorrhage complicates $2-5 \%$ of pregnancies, which approximately one-third are due to placenta previa. Placenta previa is a condition derived to an abnormal implantation of the embryos in the lower uterine segment. ${ }^{1}$ Placenta previa has been classified by the degree of encroachment upon the internal cervical os. ${ }^{2}$ In placenta previa hemorrhage is more likely to occur during third trimester, as a consequence of the development of the lower uterine segment and of the dilation of the cervix due

1. Dr. Utpala Mazumder, Associate Professor, Department of Gynae \& Obs, Dhaka Medical College Hospital, Dhaka, Bangladesh.

2. Dr. Afroza Kutubi, Associate Professor, Department of Gynae \& Obs, Dhaka Medical College Hospital, Dhaka, Bangladesh.

3. Prof. Salma Rouf, Professor and head, Department of Gynae \& Obs, Dhaka Medical College Hospital, Dhaka, Bangladesh.

Correspondence to: Dr. Utpala Mazumder, Associate Professor, Department of Gynae \& Obs, Dhaka Medical College Hospital, Dhaka, Bangladesh. Email: utpalamazumder@gmail.com to the uterine contractions; also vaginal examination may lead to an antepartum hemorrhage. Risk factors for the development of placenta previa include prior cesarean delivery, pregnancy termination, intrauterine surgery, smoking, multifetal gestation, increasing parity, maternal age and the rising rates of Cesarean section. ${ }^{3}$ Placenta previa is associated with adverse consequences for both mother and children, such as Intra-Uterine Growth Restriction (IUGR), preterm birth, antenatal and intrapartum hemorrhage, maternal blood transfusion and emergency hysterectomy. 4

\section{Classically placenta previa is divided in different forms}

$\varnothing$ Marginal: The placenta is next to cervix but does not cover the internal cervical os.

$\varnothing \quad$ Partial: The placenta covers partly the intern cervical os.

$\varnothing$ Complete: The placenta covers completely the intern cervicalos. It is estimated placenta previa has been diagnosed increasingly in recent decades, due to mostly to the widespread use of ultrasound (US). It 
occur in between 0.2 and $0.3 \%$ of third-trimester pregnancies. Falsepositive diagnoses are common in the second trimester and the term "potential placenta previa" is used to describe this situation. ${ }^{5}$ In some cases of mid-trimester potential placenta previa is more likely to migrate (phenomenon of the "rising" placenta) and ultrasound may be useful to predict this process. ${ }^{6}$ Apart from ultrasound a valid imaging modality to study and investigate placenta in antepartumperiod seems to be magnetic resonance (MR). MR imaging compared with US may be superior in some settings, especially it improves softtissue contrast and wider field of view; however, it is limited by cost, patient claustrophobia, and limited availability of both imaging unit technology and skilled image interpretation. ${ }^{7}$ About its safety, MR, as well as US, does not use ionizing radiation and appears to be a safer modality than Computed Tomography (CT), even if fetal risks remain uncertain compared to ultrasound. MR imaging allows identification of the position of placenta. However, it has been demonstrated to be less specific than color Doppler flow imaging in the diagnosis of placenta previa ${ }^{8}$, but it can add diagnostic value when further characterization is required, particularly in the setting of invasive placental processes such as placenta accreta and gestational trophoblastic disease. ${ }^{9}$

\section{Screening and diagnosis for placenta praevia: ${ }^{1,3,7}$}

1. Clinical suspicion should be raised in:

- All women with vaginal bleeding after 20 weeks of gestation.

- A high presenting part.

- An abnormal lie.

- Classically painless bleeding or bleeding provoked by (sexual intercourse), irrespective of previous imaging results, are more suggestive of a low-lying placenta but may not be present.

2. Routine ultrasound scanning at 20 weeks of gestation need to include placental localization.

3. The suspected diagnosis of placenta previa at 20 weeks of gestation by abdominal scan should be confirmed by transvaginal scan (if available, after proper counselling and patient verbal consent to be confirmed) which improve the accuracy of placental localization and are safe.

Follow up management for women with low placenta at 20 weeks of gestation:

$\varnothing \quad$ All women require follow-up imaging if the placenta covers or overlaps the cervical os at 20 weeks of gestation. $\varnothing$ Women with a previous caesarean section require a higher index of suspicion as there are two problems to exclude: placenta praevia and placenta accreta.

$\varnothing$ Placental 'apparent' migration, owing to the development of the lower uterine segment, occurs during the second and third trimesters, but is less likely to occur if the placenta is posterior or if there has been a previous caesarean section.

$\varnothing \quad$ Symptomatic cases.

\section{When should further imaging occur? ${ }^{5}$}

- Follow-up imaging can be left until 36 weeks of gestation, in cases of asymptomatic women with suspected minor praevia.

- $\quad$ Imaging should be performed at around 32 weeks of gestation, in cases with asymptomatic suspected major placenta praevia or a question of placenta accrete, to clarify the diagnosis and allow planning for thirdtrimester management, further imaging and delivery, since such pregnancies are at greater risk of prematurity and severe morbidity.

Diagnosis of morbidly adherent placenta by: ${ }^{5}$

Antenatal imaging techniques that can help to raise the suspicion of a morbidly adherent placenta should be considered in any situation where any part of the placenta lies under the previous caesarean section scar, but the definitive diagnosis can be made only at surgery. Diagnostic methods include:

1. Ultrasonography: Transvaginal and transabdominal ultrasonography are complementary diagnostic techniques and should be used as needed. Transvaginalultrasound is safe for patients with placenta previa and allows a more complete examination of the lower uterine segment.

2. Three-dimensional power Doppler has the highest sensitivity, specificity \& positive predictive value for the diagnosis.

3. Magnetic resonance imaging (MRI), occasionally use to support the diagnosis, especially in equivocal cases.

The use of ultrasound with color flow power (Doppler) can reveal the presence of large blood-filled spaces between the fetus /amniotic fluid of the lower uterus and the mother's urinary bladder, with loss of the normal myometrium. The presence of large blood vessels with pulsatile flow in the bladder wall is a likely indicator of placental invasion.

\section{Antenatal management: ${ }^{1,7}$}

1. Cases of placenta praevia in the third trimester should be counselled and her partner about the risks of preterm delivery, obstetric haemorrhage and 
indications for blood transfusion and hysterectomy should be reviewed and refusals of treatment should be dealt with effectively and documented clearly.

2. Any woman with suspected placenta praeviaaccreta should be reviewed by a consultant obstetrician (or the most senior one) in the antenatal period. The different risks and treatment options should have been discussed and a plan agreed, which should be reflected clearly in the consent form.

3. Prevention and treatment of anaemia during the antenatal period is recommended.

4. If there is a strong suggestion for the presence of abnormal placental invasion, should consider patient transfer to a tertiary perinatal care center (or the most qualified available facility). So referral should be done in the following conditions:

- Health care providers practicing at small hospitals.

- Institutions with insufficient blood bank supply.

- Inadequate availability of subspecialty and support personnel.

5. Any home-based care requires close proximity to the hospital, the constant presence of a companion and full informed consent by the woman and she should attend immediately she experiences any bleeding, contractions or pain (including vague suprapubic period-like aches).

6. Tocolysis for treatment of bleeding due to placenta praevia may be useful in selected cases. However, the agent and optimum regime are still to be determined, since beta-mimetics (10 $\mathrm{mg}$ of ritodrine every 6 hours by intramuscular injections for 7 days) were used to date, though these are known to be associated with significant adverse effects. (Prophylactic tocolysis to prevent bleeding has not been found to benefit women with placenta previa).

7. Increased risk of thromboembolism in prolong inpatient care. This need early mobilization together with the use of thromboembolic stockings and adequate hydration. Prophylactic anticoagulation in women at high risk of bleeding can be hazardous. Limiting anticoagulant thromboprophylaxis to those at high risk of thromboembolism.

Cases where vaginal delivery could be accomplished for women with a low-lying placenta: ${ }^{9}$

The mode of delivery should be based on clinical judgment supplemented by sonographic information.
A woman with a placental edge less than $2 \mathrm{~cm}$ from the internal os in the third trimester is likely to need delivery by caesarean section, but since the lower uterine segment continues to develop beyond 36 weeks of gestation, there is a place for TVS if the fetal head is engaged prior to an otherwise planned caesarean section.

Timing for elective delivery:

Elective delivery by caesarean section in asymptomatic women is notrecommended before 38 weeks of gestation for placenta praevia, or before 36-37 weeks of gestation for suspected placenta accreta.

\section{Preparations that should be made before surgery: ${ }^{4,10}$}

Placenta praevia without previous caesarean section carries a risk of massive obstetric haemorrhage and hysterectomy. The care bundle for suspected placenta accreta should be applied in all cases where there is a placenta praevia and a previous caesarean section or an anterior placenta underlying the old caesarean scar.

1. Grade of obstetrician should attend:

a. To enhance patient safety, it is important that the delivery be performed by an experienced obstetric team that includes an obstetrician, with other surgical specialists, such as urologists and a vascular surgeon (or at least general surgeon).

b. A junior doctor should not be left unsupervised when caring for these women and a senior experienced obstetrician should be scrubbed in theatre.

c. As a minimum requirement during a planned procedure for placenta praevia, a consultant obstetrician (or the most senior one) should be planned and directly supervising delivery.

2. Consultant anesthetist (or the most senior one) planned and directly supervising anesthetic plan at delivery (Assessment by the anesthesiologist should occur as early as possible before surgery).

3. Blood and blood products available (when placenta accrete is suspected, then It is advisable to have at least 4 units of packed red blood cells in the operating theatre, with ready access to further supplies, before commencing the operation. Also arrange access to supplies of clotting factors, including fresh frozen plasma. Adequate intravenous access is important; with two wide-bore venous lines inserted and an arterial line (if accessible) to measure the blood pressure accurately if there is major blood loss).

4. Multidisciplinary involvement in pre-op planning.

5. Pneumatic compression stockings should be placed preoperatively and maintained until the patient is fully ambulatory. 
6. An appropriate equipment need to be available, at least two suction devices, instruments for bowel and bladder resection should be available if needed, as should a vascular surgery set.

7. The operating theatre should be kept warm, as should the woman, since the deleterious tissue perfusion effects of blood loss are exacerbated by a drop in the body temperature.

8. Prophylactic antibiotics are indicated, with repeat doses after 2-3 hours of surgery or 1,500 $\mathrm{mL}$ of estimated blood loss.

9. Preoperative cystoscopy with placement of ureteral stents mayhelp prevent inadvertent urinary tract injury.

10. Some advice that a three-way Foley catheter be placed in the bladder through the urethra to allow irrigation, drainage, and distension of the bladder, as necessary, during dissection

11. Discussion and consent includes possible interventions (such as hysterectomy or leaving the placenta in place).

Surgical approach that should be used for suspected placenta praevia accrete: 4,11

Surgical management of placenta accreta may be individualized according to the future fertility wishes, resources available and the staff experiences.

1. Anesthetic techniques: Both general and regional have been shown to be safe in these clinical situations; the judgment of which type of technique to be used should be made on an individual basis. Though some studies confirm similar outcomes for the babies, but blood transfusion requirements were greater in the general anaesthetic group.

\section{The recommended management of suspected placenta} accrete: ${ }^{6}$

$\varnothing$ Planned preterm cesarean hysterectomy with the placenta left in situ because removal of the placenta is associated with significant hemorrhagic morbidity. However, this approach might not be considered first-line treatment for women who have a strong desire for future fertility.

$\varnothing$ The use of a midline vertical incision may be considered because it provides sufficient exposure if hysterectomy becomes necessary.A classic uterine incision, often transfundal, may be necessary to avoid the placenta and allow delivery of the infant.

$\varnothing \quad$ Ultrasound mapping of the placental attachment site, either preoperatively or intraoperatively, may be helpful. $\varnothing$ Going straight through the placenta to achieve delivery is associated with more bleeding and a high chance of hysterectomy and should be avoided.

$\varnothing$ Conservative management of placenta accreta when the woman is already bleeding is unlikely to be successful and risks wasting valuable time.

What should be done if the placenta does not separate after delivery of the baby? ${ }^{12}$

1. If the placenta fails to separate with the usual measures, leaving it in place and closing, ligating the cord close to the fetal surface, removing the cord, and leaving the placenta in situ, potentially with partial placental resection to minimize its size. This approach should be considered only when the patient has all the following criteria:

- A strong desire for future fertility.

- Hemodynamic stability.

- Normal coagulation status.

- Willing to accept the risks involved in this conservative approach.

2. Or leaving it in place, closing the uterus and proceeding to a hysterectomy.

Both associated with less blood loss than trying to separate it.

What happens if the placenta separates, or partially separates? ${ }^{13}$

The diagnosis of placenta accreta is made only if the placenta fails to separate at delivery.

1. If the placenta separates, it needs to be delivered and any haemorrhage that occurs needs to be dealt with in the normal way.

2. If the placenta partially separates, the separated portion(s) need to be delivered and any haemorrhage that occurs needs to be dealt with in the normal way.

3. Adherent portions can be left in place, but blood loss in such circumstances can be large and massive haemorrhage management needs to follow in a timely fashion.

\section{The massive haemorrhage is best managed by: ${ }^{14}$}

1. The surgical manoeuvres required in the face of massive haemorrhage associated with placenta praevia caesarean sections should be performed by appropriately experienced surgeons.

2. Calling for extra help early should be encouraged and not seen as 'losing face' of considering calling in another senior colleague(s) with superior gynaecological surgical skills early in the process. 
3. Management of massive haemorrhage should occur in the normal way, including the use of:

$\varnothing$ Uterotonic agents.

$\varnothing$ Bimanual compression or even aortic compression can buy time for extra help to arrive, or for the anaesthetist to 'catch up' haemodynamically in the unstable woman.

$\varnothing$ Advanced techniques may also be employed. Use of specific techniques that have been described for accreta include : uterine and vaginal packing with gauze, balloon tamponade, the BLynch suture, the vertical compression sutures and suturing an inverted lip of cervix over the bleeding placenta bed.

$\varnothing \quad$ Uterine and internal iliac artery ligation could be of help.

$\varnothing$ Hysterectomy if the other measures failed, but could be lifesaving with early decision for that. It may be needed especially if the patient completes her family or when there is a shortage of available blood products or with low experiences in conservative surgical procedures.

\section{Follow-up of the woman after part or the entire placenta has been retained following placenta accreta: ${ }^{13,15}$}

The woman should be warned of the risks of bleeding and infection postoperatively:

$\varnothing$ Prophylactic antibiotics may be helpful in the immediate postpartum period to reduce this risk.

$\varnothing$ Neither: Methotrexate, nor arterial embolisation reduces these risks and neither is recommended routinely.

\section{References:}

1. RCOG Green-top Guideline No. 272 of 26 (C) Royal College of Obstetricians and Gynaecologis. January 2011.

2. ACOG Committee opinion. Number 529, July 2012 (Reaffirmed 2014).
3. Reyftmann L, Nguyen A, Ristic V, Rouleau C, Mazet N, Dechaud H. [Partial uterine wall necrosis following Cho hemostatic sutures for the treatment of postpartum hemorrhage.] [Article in French] GynecolObstetFertil 2009; 37: 579-82. doi:10.1016/j.gyobfe.2008.09.025.

4. Steer P. Review the surgical approach to postpartum haemorrhag. The Obstetrician \& Gynaecologist 10. 2009; 11: 231-238.

5. Dashe JS, McIntire DD, Ramus RM, Santos-Ramos R, Twickler DM (2002) Persistence of placenta previa according to gestational age at ultrasound detection. Obstet Gynecol 99: 692-697.

6. Clark SL, Koonings PP, Phelan JP (1985) Placenta previa/ accreta and prior cesarean section. ObstetGynecol 66: 8992.

7. Tuzovi L, Djelmis J, Iliji M. Obstetric risk factors associated with placenta previa development: case-control study. Croatian Medical Journal. 2003 Dec; 44 (6): 728-33

8. Hasegawa J, Matsuoka R, Ichizuka K, Mimura T, Sekizawa A, Farina A, Okai T. Predisposing factors for massive hemorrhage during Cesarean section in patients with placenta previa. Ultrasound Obstet Gynecol. 2009 Jul; 34 (1): 80-4.15. Usta IM, Hobeika EM, Musa AA, Gabriel GE, Nassar AH. Placenta previa-accreta: risk factors and complications. Am J Obstet Gynecol. 2005 Sep; 193 (3 Pt 2): 1045-9.

9. Gilliam M, Rosenberg D, Davis F. The likelihood of placenta previa with greater number of cesarean deliveries and higher parity. ObstetGynecol 2002; 99: 976-80.

10. Usta IM, Hobeika EM, Musa AA, Gabriel GE, Nassar AH. Placenta previa-accreta: risk factors and complications. Am J Obstet Gynecol. 2005 Sep; 193 (3 Pt 2): 1045-9.

11. Johnson LG, Mueller BA, Daling JR. The relationship of placenta previa and history of induced abortion. Int J Gynaecol Obstet. 2003 May; 81(2): 191-8.

12. Hendricks MS, Chow YH, Bhagavath B, Singh K. Previous cesarean section and abortion as risk factors for developing placenta previa. J ObstetGynecol Res. 1999 Apr; 25 (2): 137-42.

13. Zaideh SM, Abu-Heija AT, El-Jallad MF (1998) Placenta praevia and accreta: analysis of a two-year experience. GynecolObstet Invest 46:96-98

14. Sheiner E, Shoham-Vardi I, Hallak M, Hershkowitz R, Katz M, Mazor M. Placenta previa: obstetric risk factors and pregnancyoutcome. J Matern Fetal Med 2001;10:414-9

15. Gielchinsky Y, Rojansky N, Fasouliotis SJ, Ezra Y. Placenta accrete - summary of 10 years: a survey of 310 cases. Placenta2002;23:210-4. 